\title{
Relation of BMI with Blood Glucose Level amongst Healthy Students of Ayub Medical College, Abbottabad
}

\author{
Nadia Haleem ${ }^{1}$, Sarwat Abbasi ${ }^{1}$, Mohammad Idress ${ }^{1}$, Zahid Irfan Marwat ${ }^{2}$, Saadia Sadiq ${ }^{3}$, Ruhila Hanif
}

\begin{abstract}
Background: Obesity is a global challenge all over the world. Body mass index is a good marker to measure the adiposity. Obesity is one of the important risk factors for type 2 diabetes mellitus. Normal random blood glucose levels are closely regulated in health with a normal range of $4.4-7.8 \mathrm{mmol} / \mathrm{l}(79-140 \mathrm{mg} / \mathrm{dl})$, despite the varying demands of food, exercise and fasting. Many diabetic patients are obese and studies suggest a strong association between the two.

Objective: To find an association of BMI with blood glucose level in undergraduate healthy students of Ayub Medical College

Material and Methods: This cross-sectional study was carried out in 2018, capillary blood samples were collected from 152 students of Ayub Medical CollegeAbbottabad to evaluate blood glucose level by Accu chek softclix ${ }^{\circledR}$ lancing device and Accu chek glucometer $^{\circledR}$, BMI was calculated by the formula (weight in $\mathrm{kg} /$ height in meters squared). Data was collected and analyzed by
\end{abstract} SPSS version 23.

Results: Total $152(100 \%)$ healthy participants with $84(55.3 \%)$ males and $68(44.7 \%)$ females included in this study. Their ages were ranged from 18-25 with a mean age of 21.02 years (min 17 max 26) having a standard deviation of 1.75 . By taking the correlation between two parameters i.e. body mass index and serum random blood glucose level by Pearson product of moment $(p=.214, r=101)$ a non-significant result was found.

Conclusion: It is concluded that there is no significant association found between two parameters (BMI and serum BGL) in healthy young adults.

Keywords: Body mass index, diabetes mellitus, Blood glucose level, Insulin.

This article may be cited as: Haleem N, Abbasi S, Idress M, Marwat IZ, Sadiq S, Hanif R. Relation of BMI with Blood Glucose Level amongst Healthy Students of Ayub Medical College, Abbottabad. J Saidu Med Coll Swat. 2020;10(1):22-26

\section{INTRODUCTION}

Obesity is one of the global and upcoming leading health challenge across the world. Mostly people of Pakistan are highly susceptible to hyperglycemia and diabetes mellitus (DM) with modest overweight, central obesity and also due to their decrease habits of exercise and physical activity level ${ }^{1}$. As reported by Kelly, the obese adults were about 396 million and overweight were 937 million respectively worldwide ${ }^{2}$. This figure is going to be doubled as compared to the past 20 years ${ }^{3}$.

Blood glucose level (BGL) is maintained and regulated within narrow limits. This system is very efficiently and finely regulated. As it is necessary to have continued and uninterrupted supply of glucose to the brain as it also utilizes ketone bodies to some extent in case of need, but the brain has an obligatory need for glucose. If we observe the postprandial regulation of BGL after meals, it is absorbed from our intestines and then get entered the blood. This raises the BGL and

1. Department of Biochemistry, Ayub Medical College Abbottabad.

2. Department of Biochemistry, Nowshera Medical College, Nowshera.

3. Department of Biochemistry, Abbottabad International Medical College, Abbottabad.

Dr Zahid Irfan Marwat, Associate Professor,

Department of Biochemistry Nowshera Medical College, Nowshera E-mail:drzahidirfan@gmail.com

Contact \# 0300-9112880 causing stimulation of specific cells of pancreas i.e islets of Langerhans whose function to secrete the specific hormone insulin. So the uptake of glucose by extrahepatic tissues (except brain) is totally dependent on insulin ${ }^{4}$. There occurred some disturbances in metabolic pathways of the body and decreased energy expenditure which results in obesity and excessive weight gain which drives elderly people to medical complications including hypertension, diabetes, cardiovascular disease and osteoarthritis ${ }^{5-7}$. Body mass index (BMI) is a good marker to measure the adiposity. It is defined as a "measure of body fat based on height and weight in adult men and women i.e weight in kilograms divided by square of height taken in meters". Body mass is divided into four categories as underweight i.e. $=18.5$, normal weight having a range of 18.5-24.9, overweight with range $25-29.9$ and obese i.e. $=30^{\circ}$. Obesity is one of the important risk factors for type $2 \mathrm{DM}$, but further research is required that why every individual having obesity do not develop type 2 $\mathrm{DM}^{10}$. Normal $\mathrm{BGL}$ are closely regulated in health with a normal range of $3.5-8.0 \mathrm{mmol} / \mathrm{l}$ (63$144 \mathrm{mg} / \mathrm{dl}$ ), despite the varying demands of food, exercise and fasting. The liver is the principal organ of glucose homeostasis, which basically involves in absorption, storage of glucose in the form of glycogen. In the process of gluconeogenesis in which the synthesis of glucose molecule takes place by combing 3carbon molecules derived from the breakdown of 
muscle glycogen (lactate), fat(glyceroll) and protein (Alanine) to be converted into a 6-carbon glucose molecule. Each day $200 \mathrm{~g}$ of glucose produced and utilized. $90 \%$ of glucose derived from glycogen and remainder from renal gluconeogenesis ${ }^{11}$. In fasting state, the action of insulin is regulation of glucose in the body and the counter-regulatory hormones are adrenaline, glucagon, growth hormone and cortisol which opposes the action of insulin causing less utilization and increased production of glucose ${ }^{12}$. It is obvious from the literature that obesity has a role in the pathogenesis of DM, and to reach such conclusion, we aimed to find an association of BMI with $B G L$ in undergraduate healthy students of Ayub Medical College, Abbottabad.

\section{MATERIALAND METHODS}

A cross-sectional study carried out in biochemistry laboratory, Ayub Medical College Abbottabad from April-august 2018. Students of age group 18-25, both males and females of MBBS were included in the study. Total of 150 participants were included on convenient sampling. Written consent was obtained from each. A predesigned questionnaire was filled by students. The study received clearance from college ethical review committee.

Two parameters i.e. Random BGL and BMI were measured. Random BGL was taken by Accu-chek softclix ${ }^{\circledR}$ lancing device. Materials required for blood glucose testing were Accu chek active meter, lancing device, lancets, test strips. The pain-free collection of capillary blood from fingertips was taken from each subjects. The lancing device had eleven different penetration depths (0.5-5.5) so it was easy to adjust the penetration. A sterilized new lancet was used for each and blood was drawn from the fingertip. 1-2 $\mu \mathrm{m}$ of blood was put onto the test strip and after approximately 5 seconds, a reading of Random $\mathrm{BGL}$ was displayed on the glucometer in $\mathrm{mg} / \mathrm{dl}$.

Under standard protocols, venous blood was drawn from few students for cross-checking the results of Accu-chek softclix glucometer. SemiAutomatic Biochemistry Analyzer (BENCH-TOPmodel URIT-810) was used in the same laboratory. Reading from both were compared and no significant differenct was noted. Body mass index of the subjects was calculated by taking their heights in meter square and weight in kilogramg by given formula.

$\mathrm{BMI}=\mathrm{Wt}$. in $\mathrm{kg} / \mathrm{Ht}$ in $\mathrm{m}^{2}$

Continuous variables were presented as mean, minimum-maximum and with standard deviation. Student T-test at 95\% confidence was used to find any association of BMI and BGL. Data were analyzed by SPSS version 23 and presented in tables and figures as frequencies and percentages.

\section{RESULTS}

Out of 152 (100\%) participants, 84 (55.3\%) were males and $68(44.7 \%)$ were females. Their ages were ranged from 18-25 with a mean age of 21.02 years ( $\min 17 \max 26$ ) having a standard deviation of 1.75. Descriptive statistics of the study population are shown in table 1. BMI was categorized into four i.e. underweight (45.4\%) normal BMI $(46.7 \%)$, overweight $(6.6 \%)$ and obese $(1.3 \%)$ shown in table 2.

\section{Table 1. Descriptive Statistics of BMI and BGL among students of Ayub Medical College} Abbottabad.

\begin{tabular}{|c|c|c|c|c|}
\hline Variables & Minimum & Maximum & Mean & Std. Deviation \\
\hline Age & 17 & 26 & 21.02 & 1.755 \\
\hline Weight $(\mathrm{kg})$ & 40.00 & 130.00 & 65.3046 & 14.27502 \\
\hline Height $\left(\mathrm{m}^{2}\right)$ & 2.05 & 335.00 & 7.5055 & 36.19031 \\
\hline BMl & 22.14 & 37.63 & 19.4861 & 4.17979 \\
\hline Blood glucose level(mg/dl) & 66.00 & 154.00 & 98.9737 & 14.13040 \\
\hline
\end{tabular}

Table 2 . Frequency of BMI Categories among students of Ayub Medical College Abbottabad.

\begin{tabular}{|c|c|c|}
\hline BMI categories & Frequency & Per cent \\
\hline Underweight & 69 & 45.4 \\
\hline Normal BMI & 71 & 46.7 \\
\hline Overweight & 10 & 6.6 \\
\hline Obese & 2 & 1.3 \\
\hline Total & 152 & 100.0 \\
\hline
\end{tabular}


Student T-test at 95\% confidence interval was applied to both parameters i.e. serum BGL and BMI. A non-significance of the difference of mean $(p=0.208)$ was found for the category; underweight $(\mathrm{SEM}=1.69284)$ and normal $\mathrm{BMI}$ $(\mathrm{SEM}=1.60665)$. Similarly, $p$-values of 0.180 and 0.208 ensued for another group i.e. BGL and BMI category of normal BMI (SEM $=1.60665)$ and overweight $(S E M=4.36196)$. However, the $p$ values of the third group between serum BGL and overweight BMI (SEM=4.36196) and obese BMI $(\mathrm{SEM}=3.50000)$ was significance 0.041 and 0.007 respectively. Table 3

By using the Pearson product of moment correlation, a coefficient of correlation " $r$ " of two variables (serum BGL and $\mathrm{BMI}$ ) resulted in a $\mathrm{p}$ value of $r<0.001$ indicating that the correlation is significant. The random BGL level taken on y-axis and $\mathrm{BMI}$ on the $\mathrm{x}$-axis. The correlation is shown by the scatter diagram. The correlation was found to be $0,(p=.214, r=-101)$ which is non-significant. Figure 1
Figure 1: linear correlation and significance of $B M I$ and serum BGL among students of Ayub Medical College Abbottabad.

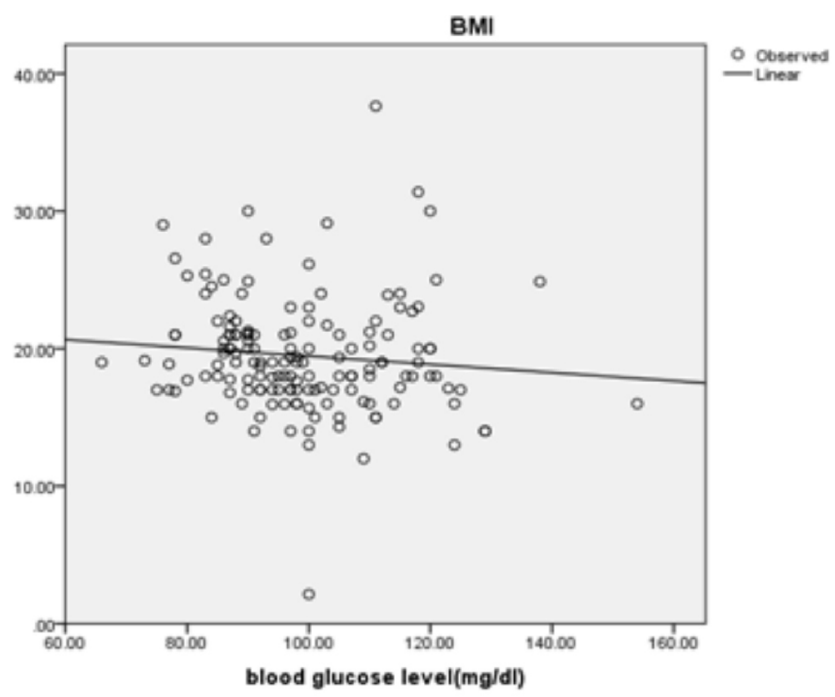

Table 3. Student T-test applied to categories of BMI and serum BGL among students of Ayub Medical College Abbottabad.

\begin{tabular}{|c|c|c|c|c|c|c|c|}
\hline $\begin{array}{l}\text { BMI } \\
\text { Category }\end{array}$ & $\mathrm{N}$ & $\begin{array}{l}\text { Mean of BGL } \pm \\
\text { S.Dev }(\mathrm{mg} / \mathrm{dl})\end{array}$ & SEM & $\mathrm{t}$ & $d f$ & sig & $\begin{array}{l}95 \% \mathrm{Cl} \text { of } \\
\text { difference } \\
\text { Lower } \\
\text { upper }\end{array}$ \\
\hline \multirow{2}{*}{$\begin{array}{l}\text { Under } \\
\text { weight-- } \\
\text { Normal } \\
\text { BMI }\end{array}$} & 69 & $101.97 \pm 14.06181$ & 1.69284 & 1.354 & 79 & .180 & $\begin{array}{l}-2.91851 \\
15.32414\end{array}$ \\
\hline & 71 & $96.80 \pm 13.53790$ & 1.60665 & 1.334 & 11.58 & .208 & $\begin{array}{l}-3.96613 \\
16.371\end{array}$ \\
\hline \multirow{2}{*}{$\begin{array}{l}\text { Normal } \\
\text { BMl--Over } \\
\text { weight }\end{array}$} & 71 & $96.80 \pm 13.53790$ & 1.60665 & 2.216 & 138 & .208 & $\begin{array}{l}.5590 \\
9.780\end{array}$ \\
\hline & 10 & $90.60 \pm 13.79372$ & 4.36196 & 2.214 & 137.38 & .208 & $\begin{array}{l}.55320 \\
9.783\end{array}$ \\
\hline \multirow{2}{*}{$\begin{array}{l}\text { Over } \\
\text { weight-- } \\
\text { Obese }\end{array}$} & 10 & $90.60 \pm 13.79372$ & 4.36196 & -2.341 & 10 & .041 & $\begin{array}{l}-46.640 \\
1.15394\end{array}$ \\
\hline & 2 & $114.50 \pm 4.94975$ & 3.50000 & -4.274 & 5.141 & .007 & $\begin{array}{l}-38.158 \\
-9.64153\end{array}$ \\
\hline
\end{tabular}




\section{DISCUSSION}

BMI is internationally accepted as a standard tool to classify obesity ${ }^{13}$. The study conducted by Agrawal et al., in his prospective study including 150 subjects of age 20-70 years of age from $\mathrm{PMCH}$, Chabad and RIMS, Ranchi including both males and females. They concluded that BMI and FBG are positively correlated and the subjects are at risk of obesity and other related conditions. As their mean BMl was in the range of 25.58 $\pm 4.77 \mathrm{~kg} / \mathrm{m}^{2}$. This was higher in females as compared to males. FBG, SBP and DBP showing significance with increasing BMI $(p=0.001$, $p=? 0.001$ and $p=? 0.0001$ respectively).

There is also a positive correlation between FBG and BMI $(r=0.751 p=0.001)^{1}$. Another study was done by Sepp $\mathrm{E}$ et al., also determine the positive correlation of BGL with BMI and reduced the proportion of cultivable bacteroids which is taking place in the gut microbiota of elderly people. The correlation of $B G L$ and $B M I$ was found to be $r=0.402, p=0.014^{14}$. In a study done by Kyriazanos et al., in which the data suggest obesity along with Helicobacter pylori infection induces an enhanced and quick response to hormone insulin which leads to decreased FBG levels, among HPpositive obese individuals as compared to HPpositive lean and thin persons ${ }^{15}$. the study conducted by Onyesom et al., in which older females in Nigerian undergraduates are at risk of increased BMI and associated abnormalities in blood glucose homeostasis. This study investigated the relationship and positive corelation between $B G L$ and BMI.

Among 253 Nigerian undergraduates having good health and with a mean age of $22.65 \pm 5.52$ years. This is indicating a positive but weak correlation between BGL and BMI among male subjects $(r=0.43 n=151$ and $p=0.05)$ and females showed strong significance $(r=0.53, n=102$, and $p=0.05)$ ${ }^{1} 6$. The data given by Cheng et al., which again shows the positive relationship between BMI and plasma glucose concentration during iatrogenic hypoglycemia in subjects having type 2 diabetes mellitus. The subjects enrolled were of above 20 years of age, having T2DM, who has documented $=70 \mathrm{mg} / \mathrm{dl}$ plasma glucose level. People having lower BMI harbored decreased plasma glucose concentration during iatrogenic hypoglycemia as compared to those individuals having high $\mathrm{BMI}$ $(30.1 \pm 9.6 \mathrm{mg} / \mathrm{dl}$ vs $38.4 \pm 12.3 \mathrm{mg} / \mathrm{dl}$, p?0.001). Subjects having lowered BMI might have compromised defense against iatrogenic hypoglycemia due to decreased release and secretion of antagonist hormones and functional disability ${ }^{1}$.

In Shimizu et al., study, relating the BMI and triglyceride to HDL ratio in relation to diabetes (Nagasaki islands study). There is a significant inverse relationship between low TG-HDL diabetes and body mass index and having a positive association between BMl and high TGHDL diabetes ${ }^{1}$. In an observational study done by Pavithra et el., in 2018, indicating a strong positive association between $\mathrm{BMI}$ and random BGL but they clearly put stress on detection and importance of early obesity ${ }^{1}$. Astudy carried out by Farooq et al., in 2017 in which they basically determine the association between BMI and serum glucose in undergraduate students. The age group taken was 17-23. Mean age of subjects was $18.57 \pm 0.99$ years, mean glucose level was $126.23 \pm 25.26 \mathrm{mg} / \mathrm{dl}$ and BMI was $24.65 \pm 6.196$. By applying the Pearson correlation test, the level of serum glucose becomes higher with increasing BMI. The correlation was found to be significant $(r=0.625, p=0.000)^{20}$. Similarly, a researcher found $0.88 \%$ prevalence of pre-diabetic cases in early age group (<25 years) and Waseem $\mathrm{M}$ et al., contradict these results but found higher level of plasma glucose level in medical students with positive Diabetes family histroy ${ }^{21,22}$.

In our study we found a correlation between BMI and serum random BGL by Pearson product of moment by SPSS 23 which was found to be .214 $(r=101)$. The $p$-value indicates no coefficient of correlation between two parameters so significant was found to be non-correlated in young adults of age 18-25 among students of Ayub Medical College Abbottabad.

\section{CONCLUSION}

It is concluded that there is no significant association found between two parameters (BMI and serum BGL). In other words, no direct effect of $\mathrm{BMI}$ is noted over BGL, yet increasing BMI (overweight, obesity) resulted in increasing BGL. This is very important because Normal BMI has no effect on BGL. Hyperglycemia can be controlled by keeping the BMI normal in young adults, as obesity is one of the most important risk factors for diabetes mellitus. Obesity is increasing in our young adults due to decreased physical activities, stressful life and bad eating habits. 


\section{REFERENCES}

1. Agrawal N, Agrawal MK, Kumara T, Kumar S. Correlation between BMI and blood glucose levels in Jharkhand population. International journal of contemporary medical research,2017; 4(8): 2454-7379.

2. Kelly T, Yang w, Chen Cs, Reynolds K, He J. Global burden of obesity in 2005 and projection to 2030 . Int J Obese (London). 2008; 32: 1431-1437.

3. James PT, Rigby N, Leach R. International obesity task force: The obesity epidemic, metabolic syndrome and future prevention strategies. Eur J Cardiovasc Prev Rehabil. 2004;11;3-8

4. Vasudevan DM, Sreekumari S, Kannan V, Jaypee Textbook of Biochemistry For Medical Students. Regulation of Blood Glucose insulin and Diabetes mellitus.(eighth edition) 2016,8; 159-179.

5. Villareal DT, Apovian CM, Kushner RF, Klein S. obesity in older adults technical review and position of the American society for nutrition and NAASO, the obesity society. Obes Res. 2005, 13:1849-63.

6. Mctigue KM, Hess R, Ziouras J. Obesity in older adults: a systemic review of the evidence for diagnosis and treatment of obesity. 2006,14; 1485-97.

7. Khannam MA, Qui C, Lindeboom W, Stratfield PK, Kabir ZN, Wahlin A.The metabolic syndrome; prevalence associatedfactors and impact on survival among older persons in rural Bangladesh. Plos one.2011,6:2025-9.

8. HU F. Obesity epidemiology. Oxford university press, 2008;87-97

9. Whitelock G, Lewington S, Sherliker P, Clarke R, Emberson J, Halsey $\mathrm{J}$ et al., Body mass index and cause-specific mortality in 9000000 adults. Collaborative analysis of 57 prospective studies. The lancet 2009; 373 (9669) :1083-96.

10. Eckel RH, Kahn SE, Ferrannini E, obesity and type $2 \mathrm{DM}$. What can be unified and what needs to be individualized. Diabetes Care. 2011;34 (6): 1426-1430.

11. Pumar K, Clarke M. Diabetes mellitus and other disorders of metabolism. $8^{\text {th }}$ edition $2012,1001-1045$.

12. Ballinger A, Patchett S. Diabetes mellitus and other disorders of metabolism. Pocket Essentials of clinical medicine Saunder Elsevier (4 ${ }^{\text {th }}$ edition), New York pp 599-634.
13. Sepp E, Kolk H, Lõivukene K, Mikelsaar M. Higher blood glucose level associated with body mass index and gut microbiota in elderly people. Microb Ecol Health Dis. 2014 Jun 3;25:10.3402/mehd.v25.22857. doi: 10.3402/mehd.v25.22857. PubMed PMID: 24936169; PubMed Central PMCID: PMC4048595.

14. Kyriazanos ID, Sfiniadakis I, Dimakos P, Gizaris V, Datsakis K, Dafnopoulou A. Impact of BMI on fasting blood glucose concentration among Helicobacter pylori carrier. Dig Dis.2003; 21(3) :262-5.

15. Innocent O, ThankGod OO, Sandra EO, Josiah IE. Correlation between body mass index and blood glucose levels among some Nigerian undergraduates. HOAJ Biology. 2013 Mar 26;2(1):4

16. Cheng PC, Shang Ren HSU, Sheh Tetu, Cheng YC, Liu $\mathrm{UH}$. Body mass index influences the plasma blood glucose concentration during iatrogenic hypoglycemia in people with type 2 diabetes mellitus: a cross-sectional study. Peer J 2018; 6: 43-48.

17. Shimizu $Y$, Nakazato $M$, Sekita T, Kadota K, Sato $S$, Koyamatsu K, et al., Body mass index and TG- to HDL Cholesterol ratio in relation to risk of diabetes. Acta Med.Nagasaki 58; 85-91.

18. K Sangeetha, Rajendran AS, Pavithra A. Correlation between $\mathrm{BMI}$ and random Blood glucose level in south Indians population. International journal of current trends in science and technology,.june 2018;8(06): 2043320438.

19. Riaz S, Shehzad S, Raza M, Hasnain, Akhtar W. Obesity as risk factor and study of obesity-related proteins in diabetes mellitus. African Journal of Biotechnology, 2009.8(5).737-744

20. Farooq M, Shoaib S, Wasim M, Amir W. Correlation between serum glucose and BMI in undergraduate students. Pakistan Journal of Medical and Health Sciences 2017. 11(3), 887-889.

21. Zafar J, Bhatti F, Akhtar N, Rasheed U, Bashir R, Humayun S, et al., Prevalence and risk factors for diabetes mellitus in a selected urban population of a city in Punjab. J Pak Med Assoc. 2011; 61 (1): 40-7.

22. Waseem M, Ahmed F, Jalal MA, Zahar Zainab, Khalid M, Aman M. Pre diabetic in young medical students. Annals 2015;21(1):39-41. 